\title{
Quality of Life: Conceptual Challenges in Exploring the Role of ICT in Active Ageing
}

\author{
Mary L M Gilhooly \\ Professor of Gerontology. Director - Brunel Institute for Ageing Studies. \\ Deputy Head of School - School of Health Sciences and Social Care, \\ Brunel University, United Kingdom \\ Kenneth J Gilhooly \\ Professor of Psychology, Department of Psychology, \\ University of Hertfordshire, United Kingdom \\ Ray B Jones \\ Professor of Health Informatics, Faculty of Health and Social Work, \\ University of Plymouth, United Kingdom
}

\begin{abstract}
The chapter aims to examine the definitional challenges associated with the term quality of life, measurement challenges, the challenges associated with enhancing quality of life, and the role of information and communication technologies (ICT) in quality of life in old age, and finally comments on the challenges of a modern information society for older people. The term quality of life started as a social scientific index of the relative well-being of whole populations, i.e. the state of states. Nowadays quality of life is more likely to be viewed as an individualized aspect of the modern psyche. This shift in conceptualization is problematic in that, if quality of life is individualized, it cannot be meaningful to assess it in the same way for everyone. Nevertheless, over the years a vast range of methods of measuring quality of life has emerged, leading to several measurement challenges. Wealth, health and social relations have all been found to be prime determinants of subjective quality of life; for ICT to enhance quality of life for older people they need to mediate the relationships between these three important factors and quality of life. To date there is relatively little evidence that ICT has improved the quality of life of older people. Suggestions are made as to why ICT is unlikely to influence life quality for older citizens. The chapter is drawn to a close by asking if quality of life is a meaningless term and if the future is bleak for old people in a modern information society. The answer to both questions is no.
\end{abstract}

Keywords: Quality of life, active ageing, ICT, older people, information society

\section{Introduction}

The last few years have seen considerable interest in exploring ways to promote active and successful ageing, healthy life expectancy, and a good quality of life in old age. Older people themselves do, of course, want to age healthily, actively, and successfully; governments want them to do so in order to slow the rising costs of health 
care, and to promote continued employment to reduce the cost of state pensions. Governments are also, to be fair, interested in active ageing in order to facilitate a decent, or even improved, 'quality of life' for their older citizens.

This chapter begins by exploring the concept 'quality of life'. The term 'quality of life' pervades discussion of health and social policy, and improving quality of life is now an avowed aim of many Western governments. Recent European Commission documents make frequent reference to improving quality of life as the goal of various initiatives. For example, the Action Plan on Information and Communication Technologies and Ageing states that "ICT can help older individuals to improve quality of life". The plan notes that the Action Plan has "not only the objectives of enabling a better quality of life for older people with significant cost-savings in health and social care, but also aims to help create a strong industrial base in Europe for ICT and ageing” (Commission of the European Communities (2007a, p 3). The Action Plan also addresses three areas of user needs - ageing well at work, ageing well in the community and ageing well at home - all of which refer to raising quality of life. The press release announcing the European Action Plan for "Ageing Well in the Information Society" states that "ICT will increasingly allow older people to stay active and productive for longer; to continue to engage in society with more accessible online services; and to enjoy a healthier and higher quality of life for longer." (press release, Commission of the European Communities, 2007b). These are bold statements - they assume that we all understand what is meant by 'quality of life' and that we have adequate methods of measuring quality of life so that we can demonstrate that ICT has improved the quality of life of older people.

The scientific literature is also replete with studies which have examined the quality of life of current cohorts of old people or the likely quality of life for the baby boomers when they reach old age. There is an enormous social science industry focussed on developing measures of quality of life. Indeed, there are journals devoted solely to research on quality of life. Yet for all this effort, there is remarkably little consensus on what the term 'quality of life' means, let alone how best to increase quality of life at a national or at an individual level. Worse still, few ask if the term is meaningful or if improvements in quality of life are a realistic outcome measure of policies or interventions.

This chapter aims to examine the definitional challenges associated with the term quality of life, measurement challenges, the challenges associated with enhancing quality of life, and the role of ICT in quality of life in old age, and finally comments on the challenges of an information society for older people.

\section{Challenges for Definition and Measurement}

\subsection{Definitional Challenges}

The term 'quality' is defined as 'goodness' (Chambers, 1961). What is interesting about the various dictionary definitions is that none define quality as synonymous with 'happiness'. Thus, in the dictionary definitions there is a suggestion that quality of life is, or perhaps even should be, about more than just happiness (Gilhooly, Gilhooly and Bowling, 2005). 
Interest in quality of life is not a recent phenomenon (Chung, Killingworth and Nolan 1997). The Greek philosophers were much taxed by notions of happiness and the good life. Aristippus, a philosopher of the fourth century BC, taught that the goal of life is to experience the maximum amount of pleasure and that happiness is the sum total of hedonic episodes. Others in the hedonic tradition include Hobbes who argued that happiness lies in the pursuit and fulfilment of human appetites and DeSade who argued that the pursuit of pleasure and sensation is the ultimate goal in life (Ryan and Deci 2001). More recently psychologists such as Kubovy (1999) have argued that hedonism includes the pleasures and preferences of the mind as well as the body.

Aristotle believed that hedonic happiness was a vulgar ideal and argued that true happiness is found in doing what is worth doing (Ryan and Deci 2001). The term eudaimonia (daimon $=$ true self) refers to this type of well-being. Eudaimonia, according to Waterman (1993), occurs when activities are congruent with deeply held values and are holistically engaged.

Self-determination theory (Ryan and Deci 2000) has embraced the concept of eudaimonia as central to well-being. Ryff and Singer (1998, 2000), in their lifespan theory of human flourishing, argue that psychological well-being is distinct from subjective well-being, with psychological well-being tapping aspects of human actualisation.

\subsubsection{Social indicators}

Although philosophers have been debating what makes for the 'good' life for hundreds of years, quality of life started as a social scientific index of the relative well-being of whole populations. Quality of life research began as an attempt to measure the state of states, i.e. population well-being. In the first half of the $20^{\text {th }}$ century, quality of life in nations was largely measured by material level related measures, for example, gross domestic product (GDP) per head.

From the 1960s there was a change to broader indicators and a change to quality of life being a characteristic of persons, as well as national prosperity. The key 'social indicators' of quality of life included the following: health and illness, income and poverty, physical environment, public order and safety, social mobility, science and art, participation and alienation and education. The 1960s was a period of growing prosperity. This was also a time of questioning economic growth as the key measure of social progress and the key goal of public policy; more might not mean better. Nevertheless this was also a period when there was widespread acceptance of active governments shaping societal structures for the greater good (Rapley, 2003).

The 1960s was also a period of growing interest in 'cost effectiveness' in medicine. Many treatments could not cure, but could only reduce pain or control symptoms. How could expenditure on such treatments be justified? When there was competition for resources, how would decisions be made on the fair distribution of resources? The late 1960s saw the introduction of the 'quality adjusted life year' movement in medicine. The idea was that while many treatments and interventions in medicine could not cure, they could improve patients' quality of life.

We see then that the term quality of life has moved a long way from the limited conceptualization of quality of life as an index of the 'state of states' (well-being of populations). Quality of life becomes much more than a social policy analogue for GDP, tying together a variety of social indicators to offer an index of the success of 
public policy. It has even been argued that it has become an integral part of marketing government policy (Rapley, 2003; Land, 2000).

\subsubsection{Subjective quality of life}

As the social indicators movement waned, interest grew in subjective perceptions of quality of life. From the beginning many theorists have argued that quality of life is inherently subjective. Moreover, as research developed, numerous paradoxical findings emerged. There were many instances of what came to be called the 'satisfaction paradox' or the 'disability paradox'. That is, there were people living in very poor living conditions who reported high levels of life satisfaction, or who were very disabled but reported being happy and having a high quality of life. Increasing wealth across the world was not leading to proportionate increases in individual perceptions of quality of life. Adaptation to objective living conditions, comparisons with others in a similar environment, aspirations, etc, were clearly influencing reports of quality of life. From the early criticisms of the whole notion that quality of life could ever be objective has grown a huge body of research focusing on individual and subjective quality of life. We cannot, of course, provide a comprehensive and systematic review of that literature, but merely highlight some of the trends and developments.

In the same way that the social indicators movement came up with lists of indicators of the quality of life of nations, research on subjective quality of life has been dominated by attempts to delineate the 'domains' of quality of life. One of the biggest attempts to delineate the domains of quality of life, as well as develop a new measure, was the World Health Organization Quality of Life (WHOQOL) project which was initiated in 1991. The aim was to develop an international, cross-culturally comparable quality of life assessment instrument which would assess individual perceptions. The scale was designed to consider the context of the rater's culture and value systems, their personal goals, standards and concerns. Developed collaboratively in a number of centres worldwide, the WHOQOL instruments have been widely fieldtested. The following broad domains are measured by the WHOQOL-BREF (a shorter version of the original instrument): physical health, psychological health, social relationships, and environment (WHO 1993). These four domains, perhaps unsurprisingly, closely match those found by other research groups. For example, Nazroo et al (2003), in a study of ethnic inequalities in quality of life at older ages, revealed six factors influencing quality of life: having a role, support networks, income and wealth, health, having time, and independence.

Of course, and as may be obvious to the reader, a major problem with attempts to determine the 'domains' of quality of life, is that there is often considerable confounding of domains and predictors. Thus researchers often determine the domains of quality of life from findings about the predictors. Others - a minority - begin with a theoretical perspective. For example, Blane et al's (2002) quality of life measure was based on the theory of needs satisfaction and included (1) control (2) autonomy, (3) self realisation and (4) pleasure. Blane and his colleagues argued that quality of life measures often used 'proxy' measures, such as health, financial status, or social networks (Hyde et al, 2001, 2003).

As a consequence of the broadening of the definition and scope of the term, the term 'quality of life' has become increasingly complex, indeed, slippery (Rapley (2003). It is now used to describe everything. It should not, therefore, surprise us to 
find that there is now no agreed definition. Because there is no agreed definition there is no agreed method of measurement.

\subsection{Measurement Challenges}

Research on how quality of life is affected by various factors (such as policy decisions) depends on having some way of measuring quality of life. However, there is a vast range of methods of measuring quality of life and some difficult issues arise in measuring this complex variable (Gilhooly, Gilhooly and Bowling, 2005). The focus here is on subjective measures as against presumed objective indicators.

\subsubsection{Responding to Quality of Life questions}

Quality of life research depends heavily on individuals' responses to rather complex and sometimes vague questions such as 'How satisfied are you with your life as a whole these days? Very satisfied, satisfied, not satisfied, not at all satisfied?' What processes are involved in answering such questions? Do people maintain internal 'mental meters' of subjective well-being from which values can be read and related to the questionnaire scale? That view cannot be sustained since responses are susceptible to a wide range of contextual factors. It seems that responses are constructed 'on-line' as the demand arises by using information that comes to mind when the question is asked. That short term test-retest reliability for subjective well-being is often low ( $r=.4$ to .6 ), even over only a one hour gap, is indicative of the importance of context effects. It has been shown that minor events, such as finding a low value coin or changes to the order of questions, can markedly affect responses (Schwartz 1987; Schwartz and Strack 1991).

\subsubsection{Accessibility}

A typical quality of life item might be 'Taking all things together, how would you say things are these days?' In answering such questions it is not feasible for people to exhaustively review all aspects of their lives to derive an overall judgement. Rather, it seems that people tend to retrieve what they judge to be sufficient information on which to base an answer. In doing so, they use information that is readily accessible to them at the time of the question. Accessibility of information depends on the recency with which the information has been previously accessed and on the frequency with which it has been accessed. For example, if one has been very recently reminded of a pleasant childhood experience, that information will be readily accessible and, thus, may affect judgements about satisfaction with life as a whole. Or, one may be dwelling frequently on negative relationships with work colleagues and that problem would be highly accessible and so affect judgements of overall life satisfaction.

Effects of accessibility on life satisfaction and well-being judgements have been demonstrated in a number of studies. For example, Strack, Martin and Schwartz (1988) asked undergraduate students questions about dating frequency and general life satisfaction. It was found that if the dating question came second then the correlation between dating frequency and life satisfaction was a nonsignificant -0.12 . If the dating question was placed before the life satisfaction question, then the correlation between dating and life satisfaction increased to a substantial .66. Similar results were found for other groups when the questions concerned marital satisfaction and life satisfaction. Gilhooly et al (2002a) found that overall quality of life ratings in a sample of older 
people were much higher when quality of life was rated before ratings of the quality of public transport. It is likely that prior negative thoughts about difficulties of using public transport influenced thoughts about overall quality of life. Overall, the results indicate that questions preceding general life satisfaction questions bring information to mind that affects the overall life satisfaction judgement.

\subsubsection{Using accessible information: assimilation, contrast and duration effects}

Retrieved information about the same event may have different effects depending on how it is used. A recent negative event will likely be assimilated into a judgement of 'my life now' and so reduce reported satisfaction; but, a distant negative event may form a contrast with the current state of affairs and so lead to a boosting of currently reported satisfaction. For example, Elder (1974) found that older people in the USA who had been young in the Great Depression typically reported higher subjective wellbeing the more they had suffered poor economic conditions as teenagers. Similarly, Runyan (1980) found that upwardly mobile people remembered childhood as less satisfactory than downwardly mobile individuals, presumably by contrast with their current circumstances.

In assessing extended episodes people tend to make particular use of affective peaks and the affective value of the end stage of the event and largely ignore duration. Kahneman et al. (1993) reported that people who underwent an unpleasant medical procedure actually preferred longer periods of discomfort to shorter periods if the end stage was a gradual drop in discomfort as against an abrupt drop. So, sometimes more pain is preferred to less! Information about duration of the painful episodes seems to be neglected. Judgements of pain tend to follow a 'peak and end ' heuristic which only takes these two aspects into account. Similar patterns have also been found in judgements of pleasant episodes using films as stimuli (Kahneman et al., 1993). So, the effects of a three year negative period (for example, being unemployed) on overall life satisfaction may not be much more than that of a shorter period, given use of the 'peak and end' heuristic which ignores duration.

\subsubsection{Mood states}

Mood state at the time that quality of life judgements are made can affect responses. Being tested in situations that typically induce positive moods such as in a pleasant room or when the sun is shining has been found to affect subjective well-being judgements (Schwartz. 1987; Schwartz and Clore 1983). One possibility is that moods increase accessibility of mood congruent information. People in a happy mood retrieve happy memories more easily and those in a sad mood more readily retrieve sad memories. Hence, the accessible information is congruent with mood and affects judgements accordingly. Another way in which mood effects might arise is that mood itself may be used as a quick basis for responding. A 'mood heuristic' could be used so that the respondent reasons 'If I feel good at this moment it is likely that my life is generally good.' In this way an answer can very quickly be given to a general quality of life question without extensive cognitive processing. Consistent with this view is the finding of Ross et al. (1986) who asked participants to explain their life satisfaction judgements and found that a majority referred to their current affective state saying for example 'Well, I feel good'.

It seems likely that use of the 'mood heuristic' would tend to occur with the more cognitively demanding questions that request an overall assessment since the heuristic 
offers a low effort short cut. It would probably be less likely when the questions are more specific. Indeed, Schwartz (1987) found that the results of a football game important to the participants (which affected mood) influenced overall life satisfaction responses but not satisfaction judgements regarding the more specific domains of work and income.

\subsubsection{Reporting and editing}

It is notable that self reported quality of life levels are typically quite high. In a survey and recalibration of a large number of studies from across the world involving some 1.1 million participants, Myers and Diener (1996) found that the average rated happiness was nearly 7 on a $0-10$ point scale where 0 was very unhappy, 5 was neutral and 10 was the high extreme. A large study using the 'faces' scale in Detroit (Andrews and Withey, 1976) found that $90 \%$ picked one of the happy faces as representing how they felt about their lives as a whole. Similarly, Gilhooly et al (2002b, 2003), in a study on mid-life risk factors for declines in cognitive functioning in old age, found that $89 \%$ of their sample of 145 older people chose one of the happy faces to represent their current quality of life. Likewise, in their study on transport and quality of life, Gilhooly et al. (2002a) found that ratings on the faces scales of quality of life were skewed toward the 'delighted' end of the scale. Bowling and Gabriel (2004) reported that almost $80 \%$ of their 999 older respondents used the highest three points on a seven point scale to indicate their quality of life. Blane et al (2002) reported a mean of 42.2 on a scale with a range $0-57$ on the quality of life measure they developed, again indicating some skewing towards the positive end of the scale with most study participants reporting reasonably good quality of life. The typically skewed distributions of quality of life ratings may partly reflect an editing process whereby people try to present themselves in a positive light. In other words, there is scope for the operation of social desirability effects in reporting quality of life.

Normally, social desirability effects are stronger in face to face questioning as against more anonymous forms of testing (De Maio, 1984). Smith (1979) found that higher well-being was reported in face to face conditions as compared with surveys by postal means. Strack et al. (1990) found that self-presentation was affected by contextual effects. Higher well-being was reported in face to face interviews versus confidential self report, except when the interviewer was clearly handicapped. This may reflect a reluctance to stress how good one's life is to someone who appears less fortunate. However, if the handicapped person was present in the room as another participant filling in their own questionnaire then subjective well-being reports were increased, presumably through a contrast effect. Comparing and contrasting one's quality of life with other people is a common phenomenon, even if these other people are not present. For example, Beaumont, Kenealy and Murrell (2003a), in their study on quality of life of healthy older adults, noted that their study participants overwhelmingly adopted downward social comparison strategies when considering their quality of life. In other words, those reporting higher quality of life were more likely to see themselves as unlike those who were worse off. "A lot of people here are a lot worse off than me." and "[You] gain a heightened awareness of all those who are in a worse position.", were typical of the social comparison that participants in Beaumont et al's (2003b) study made.

It appears then that self reports of quality of life may be edited and reported as somewhat higher than is privately felt for reasons of social desirability. However, it 
may be noted that measures of how susceptible people are to social desirability effects in general are only weakly correlated (.20) with well-being reports according to Diener (1984). Overall, situational factors of the testing procedure are generally more influential than individual difference factors.

\section{Challenges for Enhancing Quality of Life in Ageing Societies}

Before we can answer questions about whether or not ICT can improve quality of life in old age, it is necessary to consider what is known about the predictors of quality of life and to what extent governments or individuals can do anything to alter these predictors. If, for example, gender, or stable personality characteristics, accounted for most of the variance in perceptions of individualized quality of life, there would be little scope for governments to bring about changes in how their populations view their quality of life.

\subsection{Predictors of Quality of Life}

There are thousands of research articles looking at the predictors of quality of life. Three factors consistently emerge as the main predictors, namely wealth, health and social relationships, though not necessarily in that order. Government policies can impact on all three. Taxation policies have an impact on disposable income and even earned income is influenced by government policies. Income influences health and health influences the ability to work. Income influences the ability to keep in contact with and visit family and friends, as well as helps determine the nature of one's recreational activities and, hence, one's social networks. The built environment has an impact on social networks.

In this section we shall look at some of the research on the impact of wealth, health and social relations on perceived quality of life. Special emphasis will be placed on quality of life for older people. However, before examining the research on wealth, health and social relations it is necessary to briefly consider the research on the role of personality in perceptions of subjective quality of life. This is an interesting and somewhat controversial area of research and theory.

\subsubsection{Personality}

It has been argued for some years that quality of life, or more specifically happiness and life satisfaction, is a dispositional characteristic (Costa and McCrae, 1980; Costa et $a l, 1987)$ which is not only stable across the life span, but is biologically determined (Diener, 2000). The personality characteristics most consistently and strongly related to subjective well-being are extraversion and neuroticism. Optimism and self-esteem have also been found to be significantly correlated with subjective well-being, though the direction of causality has not been determined (Scheier and Carver, 1985; Scheier et al, 1989; Evans, et al 1993c). Locus of control has also been linked to well-being (Brandstadter and Baltes-Gotz, 1990; Young, 1991).

Temperament models of the relationship between personality and well-being posit that there are biological 'set points' of emotional experiences, that there are biological determinants for emotional reactions to stimuli, and/or that those with certain personalities are able to wrest more rewards form the environment (Diener and Lucas, 
1999). Evans (1994), following on from Lazarus (1991a, 1991b), has proposed a model in which cognitive appraisal of life in general, as well as specific domains, has a reciprocal relationship with quality of life. Lazarus defines cognitive appraisal as an evaluation of what is believed about the significance of what is happening for wellbeing. Thus, according to Evans, personality impacts on general and domain specific skills, affective tone and affect, and social support, all of which are linked with cognitive appraisal. In the Evans model cognitive appraisal both determines, and is determined by, quality of life.

Although there are many references to improving quality of life in policy documents, there has been a general reluctance to suggest that quality of life is identical to hedonic happiness or even eudaimonia. Perhaps this is because of an intuitive belief, now supported by a growing body of research, that happiness and psychological well being are determined by, or mediated by personality characteristics, over which governments have little influence. What, perhaps, can be hoped for by policy makers is that policy can alter the environment, service provision, distribution of wealth, etc., and that such factors will influence perceptions of quality of life. The level of happiness or subjective well-being that results will, however, be determined, it could be argued, by individual personality traits.

\subsubsection{Wealth}

Does money make older people happy? Yes, up to a point. On average people living in the poorest nations report lower levels of happiness than those in the richest nations. Studies comparing nations fairly consistently reveal that where low income threatens basic human needs, being relatively well off predicts greater well-being. However, where gross national product is more than $\$ 8,000$ per person, the correlation between national wealth and well-being evaporates (Myers, 2000). The picture is, however, complicated by the fact that wealth, civil rights, literacy and years of democracy are confounded.

While many would deny that money could buy them happiness, if asked 'Would a little more money make you a little happier?' many say yes (Myers, 2000). A University of Michigan survey asking, 'What would improve your quality of life?' revealed that 'more money' was the most frequent response (Campbell, 1981). Studies of individuals have also revealed that very rich Americans are only slightly happier than the average American. The overall conclusion drawn by Myers (2000), when reviewing the relationship between money and happiness, is that happiness depends less on exterior things than might be expected. Indeed, as noted by Ryan and Deci (2001), several studies have indicated that the more people focus on financial and materialistic goals, the lower their well-being.

Wealth in ageing societies

Most of the research on the links between wealth and happiness has been with the population as a whole, rather than older people. However, a number of surveys of older people have examined the role of income and wealth on health and measures related to quality of life in retirement. Unsurprisingly, post-retirement income has been found to predict retirement quality (Quick and Moen, 1998). Post-retirement income has generally found to be more predictive of quality of life for women than for men; this is largely because more retired women than men are living at or below poverty levels. At population levels, a country's welfare regime, in terms of capacity to protect vulnerable older people, has the most significant effect at older ages. 
Netuveli (2007), comparing 15 countries in Europe and the USA, found that the type of welfare regime explains $63 \%$ of the variation between countries in their quality of life. The social democratic welfare regimes (e.g. Denmark and Sweden) do best, while USSR type regimes have the worst influence on the quality of life of older citizens, followed by post-communist and familialistic type regimes (Netuveli, 2007).

There are three sources of new income in old age: a state pension, an occupational pension, and employment. In addition, many people now turn their capital (e.g. house) into income.

Pension provision by the state - The wealthiest countries in the world allow old people to stop working by providing state pensions to enable them to independently survive financially, i.e. to not have to rely on family financial support as used to be the case. Indeed, some of the wealthiest even provide state pensions to those over set ages, usually 60 or 65 years, who are still in employment. When retirement was first introduced few people lived beyond the set retirement age. Pensions for old people were brought in when countries no longer viewed it as acceptable to force those older people with no family to provide for them financially into 'work houses' for the destitute.

Pension provision by employers - The coverage of occupational pensions steadily increased in most Western countries from the 1930s to the late 1960s, with some decrease and stabilization since (Walker, 1993). In many countries occupational pensions are now far more important in providing for a financially secure old age than the state pension. Many Western governments have moved towards the idea that the state pension is a basic minimum and people must make financial provision for old age via an occupational pension, savings, and other investments. Because for many people this is very difficult, especially in light of recent problems associated with the collapse of pension funds and general distrust in the companies providing occupational pensions, and because older people are now healthier than in the past, governments are increasingly moving to the idea that people should work longer. The UK government, for example, is considering moving the retirement age (for the state pension) to age 67 (Pensions Commission 2004, 2005, 2006). Encouraging older adults, indeed requiring them, to work raises very important issues in relation to training and skills development, especially in relation to ICT and the information society.

Opportunities to work - Wealth in old age can also be maintained, or even increased, via employment opportunities. Although it was probably never intended that the introduction of state pensions would bring about a situation in which older adults were denied opportunities to work, most employers in Western countries moved towards mandatory retirement somewhere between the ages of 60-65 years. Anti-age discrimination laws were first enacted in the United States of America in 1967. In 1977 New South Wales was the first state in Australia to legislate against age discrimination, with other states following in the 1980s and 1990s. Age discrimination legislation was introduced in the UK in 2006 with the Employment Equality (age) Regulations. Aimed largely at helping those (mainly men) aged 50-55 years obtain employment when made redundant, current UK legislation only allows those over retirement age to 'ask' if they can stay on, i.e. there is no requirement to keep older workers in employment. Heyday, part of Age Concern England, has brought a court case challenging the law allowing mandatory retirement. The decision is expected from the European Court of Justice in 2008 (Age Concern England, 2007).

A frequently used reason for not employing older workers is that they do not have the ICT skills necessary for modern jobs. Of course, one of the main reasons why 
older workers do not have up-to-date ICT skills is because employers are reluctant to invest training budgets in older workers who may only work a few more years. The new UK anti-age discrimination regulations/laws will, however, require employers to offer older employees the same training opportunities as younger employees, though it does not guarantee employees any rights to employment after the age of retirement.

As noted above, many governments are actively encouraging older people to work longer. It is often assumed that older people want to continue working, and that few, largely those in manual occupations, or those already in poor health, want to cease working at the normal age of retirement. There is, however, little evidence from those countries which have had anti-age discrimination laws for many years that age discrimination legislation has been effective, nor is there much evidence that, given the opportunity, older people have eagerly embraced continued employment (JRF, 2001).

If continued employment in old age is important to governments, how is this to be facilitated given that there is growing evidence that the majority of people do not appear to want to work past the age of 65 years? And even if a substantial number of older adults want to continue working, how will employers and older people themselves manage the demands of modern jobs given the declines in cognitive functioning with age? It is not only important that employers ensure that older workers have opportunities to learn new skills, but that when planning skills updating and training opportunities that consideration is given to age changes in memory, intelligence, learning, and problem solving. Learning new skills at work is going to be stressful for employees if employers do not take these age changes into consideration.

\subsubsection{Health}

Is health the main predictor of quality of life in old age? Yes, almost all research shows that health is a prime determinant of subjective quality of life. For young people without chronic conditions health is viewed as somewhat less important than wealth, but for older people poor health is associated with lower ratings of quality of life. Health is, of course, a complex construct. The World Health Organization (2007) defines health as ".... a state of complete physical, mental and social well being and not merely the absence of disease or infirmity...” (p 1). Thus, to examine the impact of health on perceptions of quality of life, we need to consider research on physical and mental health, including cognitive functioning, as well as social well-being. Before we begin, however, we must remind ourselves that there is, of course, a very large body of research showing that wealth is closely linked to health, with those who are wealthier exhibiting better health (Wilkinson, 1996; McCarron, et al 1994). Causality can go either direction - poverty causes poor health or poor health causes poverty. Although there is some evidence that poor mental health does indeed cause 'drift' down the social class ladder, most researchers are of the view that the direction of causality is from poverty to poor health (Bennett, 2003; Blane et al 1993). It is important to keep social class inequalities in health in mind when considering the role of health in quality of life.

\section{Physical health}

Almost all conceptualizations of 'successful' ageing include some notion of good physical health. There are, of course, many who argue that one can age successfully even if disabled, and with multiple chronic diseases. When conceptualized in this way successful ageing is about coping with the negative consequences of ageing. Nevertheless, medical practitioners, specialists in public health and health promotion, 
and policy makers are very interested in what can be done, both at an individual level and at a population level, to bring about a long life free of disease and disability. Underlying this debate is the question of whether it is possible to age without disease. It is often said that soon we shall be able to prevent and cure most of the diseases that currently kill people and that, as a consequence human life expectancy could increase to 150,200 , maybe 400 years. In other words, it is proposed that human life span, as contrasted with life expectancy, is much longer than is currently supposed. At the moment the upper limit for the human life span is thought to be around 125 years (Cristofalo et al, 1999). Elizabeth "Pampo" Israel, believed to be (never, however, verified) the world's oldest living person, celebrated her $128^{\text {th }}$ birthday in January 2003. Israel's next-door neighbour, Rose Pere was 118 years old at the time. Both women are from Dominica, which is home to 22 documented centenarians. Ms Jeanne Calment, the oldest (verified) person living in 1997, died at the age of 122. The key to the future quality of life of an ageing global population may rest, to a large extent on how tightly linked ageing rates are to ageing dependent diseases (Gilhooly and McDonach, 2006).

Ageing without disease

Age is the main risk factor for almost all illness, yet many argue that it is not inevitable that people will experience disease or disability in old age and that much can be done in relation to both cure and prevention. There is, of course, considerable evidence that interventions such as health and safety laws increase the likelihood that people might make it into old age. The introduction of seat belts, plus the requirement that they be used, has noticeably cut the car accident death rate. Individual behaviour also influences the likelihood of surviving to retirement. Smokers are much less likely to reach an advanced old age than non-smokers, and heavy alcohol consumption is a major risk factor for premature death.

Any examination of the incidence and prevalence of disease by age shows a stark pattern; almost all diseases show an increase with age (Manton, 1989; Wood and Bain, 2001). Some diseases peak in childhood (e.g. lymphocytic leukaemia) and mid-life (polycystic kidney disease, multiple sclerosis and systemic lupus), but most peak in old age. Brody (1990) has proposed that the term 'age-related' be used for diseases that peak at younger ages and 'age-dependent' for those that peak in old age. As noted by Solomon (1999), this does not mean that ageing is the sole aetiology, but that the ageing process is a potent predisposing factor for disease and conditions whose aetiology is multifactorial. Of interest is whether or not diseases are age-dependent because they are time-related; that is, time is required for the disease process to mature. Some genetic disorders are of this nature and, hence, are not really to do with ageing processes.

Mortality increases exponentially with age from a late childhood nadir to approximately age 85, with a doubling time of around 8.5 years. Ageing-dependent diseases also follow this same Gompertzian law of linear relationship between the log of age-specific incidence and chronological age (Gompertz, 1825). Interestingly, evidence is accumulating that Gompertzian dynamics disappear after the age of 85-90 years. From around 85 years the mortality rate is more or less constant with advancing age. There are five 'model' ageing-dependent diseases, (1) ischaemic heart disease, (2) malignant neoplasms, (3) diabetes mellitus, (4) osteoarthritis and (5) Alzheimer's disease that all demonstrate these relationships (Solomon, 1999). 
Alzheimer's disease is probably the most feared of all the age associated diseases and the one that most would say leads to a poor quality of life. The annual incidence for Alzheimer's disease is 1.4 per 1,000 in the seventh decade, 6.4 per 1,000 in the eighth decade and 20.5 per 1,000 in those 80 years and over. These figures describe a Gompertzian exponential with a doubling time of 5-6 years from age 60-90 years; there is some evidence of a decreasing slope after age 90 . The most exciting research development in recent years is the growing body of evidence that vascular disease is a risk factor for dementia of the Alzheimer's type. The risk factors for vascular disease are well known and many (e.g. hypertension, alcohol consumption) can be moderated (Gow and Gilhooly, 2003).

We see then that ageing and disease are inextricably linked. As noted by Miller (1994), "Aging is a process that converts healthy adults into frail ones, with diminished reserve in most physiological systems and an exponentially increasing vulnerability to most diseases and death.” If, as the exponential rise in disease rates with age suggests, it is unlikely that one can age without disease - and we do not yet know how to prevent or slow down ageing - is it possible to compress morbidity into the last few months, or at least years, of life in order to facilitate a higher quality of life for those who live very long lives?

\section{Compression of morbidity}

The research evidence on compression of morbidity is unclear as to how much progress has been made towards this goal. Scotland, for example, seems not to have witnessed much in the way of compression of morbidity. In England and Wales the expectation of life without limiting longstanding illness has shown minimal change between 1980 and 1998. The expectation of life without moderate disability has increased in line with the increase in total life expectancy in men, but has shown minimal change in women. Thus, for women the absolute time spent with moderate disability has increased (Wood and Bane 2001). The United States has seen a decrease in major disabilities associated with old age, though this appears to have been accompanied by an increase in minor disabilities. Health inequalities, however, appear to be increasing, which may partially account for compression of morbidity. However, the future may be less rosy because of rising levels of obesity, meaning that the baby boomers may not see any compression of morbidity. Indeed, the rising levels of obesity might even mean that for this large cohort there will be an extension downwards of morbidity and disability levels.

Given the large, and growing, body of research showing that physical health is a prime determinant of subjective quality of life, it is somewhat disturbing to find so little evidence of progress in compressing morbidity closer to death. Moreover, the close link between ageing and disease strongly suggests that it is unlikely that it is possible to age without disease. Perhaps a way will be found to prevent or slow down ageing, but even if it was possible (and many policy and ethical issues would arise from slowing or preventing ageing), this is something that is far into the future.

Mental health

Although the term mental illness covers a range of disorders, e.g. schizophrenia, obsessive-compulsive disorder, the disorder of most interest to gerontologists is depression. For many years there has been debate about whether or not depression increases with age. While there are many publications that boldly state that depression rates rise dramatically with age, that depression reaches epidemic proportions in old age, such statements are rarely accompanied by references. Determining incidence 
levels of depression amongst community dwelling elderly people is, of course, problematic. Most measures of clinical depression contain questions about changes in functions such as sleep patterns and bowel movements which are indicative of depression in young people but are very common in old age (e.g. waking early and constipation). Also problematic when attempting to determine not only prevalence levels, but whether or not depression is a predictor of low quality of life in old age, is the fact that most studies of depression are cross-sectional, rather than longitudinal, making it difficult to disentangle cohort and ageing effects. Clinical studies have revealed rather different results from self-report community studies, and longitudinal studies also give a different picture. Clinical studies suggest fewer differences between younger and old people in rates of depression (Teri, 1991).

The findings that are emerging from longitudinal studies are, however, beginning to shed more light on this issue. For example, the US Health and Retirement Study (2007) found that the rate of severe depression rises with age. The rate for severe depression was about $15 \%$ within each 10 year age band between the ages of 55 and 84; for those aged 85 and above the rate rose to $20 \%$. Depression is, of course, associated with unhappiness and, presumably results in a poor, or at least lower, quality of life. However, these states are conflated. We do not know if depression causes poor quality of life because depression is assumed to be indicative of poor life quality.

Importantly, depression is strongly correlated with physical health (Jarvik and Perl, 1981) and may also be a side-effect of medications. Admission to a care home has been found to be associated with an increase in depressive symptoms, but since poor and deteriorating physical health often precipitates relocation to a care home, it is hard to know which factor is of greatest importance (Kasl and Rosenfield, 1980). Of course, much of what is called depression in the elderly may be a reaction to the many stresses and losses of old age. Loneliness often increases in old age because of the death of one's spouse and friends; loneliness has been found to be strongly linked to depression in old age (Prince et al, 1997). Blazer and Williams, (1980) note that what is often taken to be clinical depression actually represents decreased life satisfaction and periodic episodes of grief. Contrary to common belief, retirement is not linked with increased rates of depression or suicide (Atchley, 1980; George, 1980).

Because psychiatric conditions, in particular clinical depression, account for substantial disease morbidity in industrialized countries, and because mental health problems are expected to rise in developing countries with increasing life expectancy, it is most important that the complex relationships between ageing, mental health and quality of life are further researched.

\section{Cognitive functioning}

The dramatic decline in cognitive functioning that accompanies dementia of the Alzheimer's type is feared by many older adults, and is a cause of considerable anxiety for those with dementia. The Health and Retirement Study (2007), a well-designed US longitudinal study of more than 20,000 older adults which started in 1992, found that some $10 \%$ of people age 70 years and older have moderate to severe cognitive impairment, with prevalence rising steeply with age (Suthers et al, 2003; National Institute on Aging, 2007). Although it is generally believed that dementia leads to a poor quality of life, there has been almost no research asking people with dementia about their quality of life. It is also assumed that the more normal changes in cognitive functioning that accompany ageing also decrease quality of life and it is this assumption which we shall now briefly examine. 
Marked declines in fluid intelligence, the ability to solve abstract problems, occur with age, though to some extent this is compensated for by increases in crystallised intelligence, cumulative and learned information (Horn, 1982; Gilhooly and Lightbody, 1999). Gow et al (2005) in an interesting study in Edinburgh, Scotland, reported that cognitive ability at age 79, as well as changes in cognition over a lifetime, did not predict satisfaction with life in old age. Other studies have also found that current cognitive ability in old age does not appear to be significantly related to satisfaction with or reported quality of life. It may be, however, that this is because cognitive ability has been measured using tests of abstract reasoning, rather the solving of practical, 'real world' problems. The ability to solve problems in the real world could be expected to be predictive of quality of life.

Gilhooly et al (2007), in a Scottish study examining mid-life risk factors for cognitive functioning in old age, found that, whilst performance on abstract problem solving tasks did not correlate with ratings of quality of life, performance on real-world problem solving tasks did. Interestingly, self ratings of cognitive functioning were significantly associated with perceived quality of life, with those rating themselves as having lower cognitive functioning rating their quality of life as lower.

\subsubsection{Social relations and wellbeing}

The past thirty years of research in health and the social sciences has established the importance of social relations for health and well-being (Cohen, 2004; Kafetsios, 2006). A large social network does not, of course, mean that one will feel socially supported or feel able to confide in one or more people. A social network is a 'set of linkages among identified groups of people, the characteristics of which have some explanatory power of the social behaviour of the people involved. A social network is a set of people with who one maintains contact and has some form of social bond (Mitchell, 1969 in Bowling et al, 1991).

Social support is defined as the "interactive process in which emotional, instrumental, or financial aid is obtained from one's social network. Support exists only if it leads to certain beliefs, such as being cared for and loved, esteemed and being a member of a network of mutual obligations (Cobb, 1976; Wallston et al, 1983). Willis (1985) has defined social support as consisting of four types: (1) esteem support, (2) informational support, (3) social companionship and (4) instrumental support. As people age social networks tend to reduce to largely networks of kin, and kin provide most of the help that elderly people require (Wenger, 1984).

Research has consistently shown that people who report having a confidant have higher life satisfaction, lower levels of depression, and are better able to adapt to gradual social losses such as widowhood and retirement. Social ties and help are critical factors in the maintenance of independence (Wan, 1987), one of the important domains of quality of life described in the research by Blane and his colleagues (2002). The quality, rather than quantity, of support and social interaction, has been found to be most important for older people. For example, Leveton et al (1979) found that perceived accessibility of support predicted feelings of well-being among a sample of elderly people, whereas frequency of social contact did not. In a study on the living arrangements of Canadian Chinese elders, Gee (2000) found complex interactions between marital status, intergenerational residency and gender, and different results depending on the measure used to examine quality of life. For example, for widows, 
living arrangements made a difference to 'well-being', but not 'life satisfaction'. What, however, really mattered was age and health status.

Nevertheless, the research findings on the links between social relations and quality of life have not always been consistent. This inconsistency has partly been due to different methods of measuring 'quality of life'. In addition, many of the studies on the relationship between social networks, social support and quality of life, no matter how defined or measured, have not examined the relationship in conjunction with physical health status. In one study which was able to do so, it was found that health status, as measured by functional ability and number of health problems, was a more powerful predictor of current and overall 'life satisfaction' than objectives social network variables such as size, number of friends, relatives and density (Bowling and Browne, 1991). Interestingly, Bowling, Farquhar and Browne (1991) found that health status was the most powerful predictor of life satisfaction in two areas of England (City and Hackney) but not in another, less urbanized area (Braintree). The analysis in this study also revealed that the social network variables were weak predictors of life satisfaction. Bowling and her colleagues speculated that physical health might be more important to the life satisfaction of older people living in inner city areas because poor health and functional ability is a greater handicap for people living in dense, higher urbanized areas where housing is more likely to consist of houses which have been converted into flats, or tower blocks of flats involving the need to negotiate stairs, plus reduced opportunity to relax in open spaces.

\subsection{ICT and Quality of Life in Old Age}

If, as we believe, ageing and disease are inextricably linked, it is highly unlikely that governments can do anything to ensure that all very old people remain in good physical and cognitive health up to the time of death. What, however, might be within the realm of possibility is producing environments and forms of care that compensate for morbidity and disability in old age. Recent years have seen considerable interest in the role of ICT in active and healthy ageing and as a mechanism for maintaining quality of life in old age. In the next section we shall consider some of the evidence on the role of ICT in quality of life. The issues considered here are dealt with in greater detail in other chapters of this book.

\subsubsection{General personal use of computers has no impact on quality of life}

In 2006, Anna Dickinson and Peter Gregor published an excellent critique of the limited literature of the effect of computer use by older people on their quality of life. They identified studies that set out to evaluate the impact of general personal use of computers on the 'wellbeing' or 'quality of life' of adults over the age of 50 years, in studies that used a quantitative methodology. They also identified and examined all papers that cited these studies. They identified 12 primary studies dating from 1980 to 2004 and numerous secondary papers that (mis)used them.

Many of the original papers had weaknesses in them that have either received insufficient discussion in the original or have been overlooked by the authors of the secondary papers that cite them. For example, in the 1980 publication by Danowski and Sacks statistically significant differences were found between pre- and postintervention answers to the questions: "Do you think using the computer would make you more confident in yourself?" and "Do you think using the computer would make 
you feel less alone?'’. The pre-intervention questionnaire was answered by 30 participants, and the post-intervention by only 13; Danowski and Sacks themselves admit that a possible explanation is that those with more positive attitudes would have been more likely to continue in their participation and answer the second questionnaire. However, those citing the study for example, (Jones and Bavin 1998; Namazi,, McClintic, 2003; Saunders, 2004) fail to display such caution.

Similarly, other studies with limitations because of study design are used uncritically by secondary authors when citing. Two studies (White et al, 1999; White et al, 2002) by White, widely cited as providing evidence that computer use reduces loneliness, probably lend more support to the argument that training and interaction are the most important aspects of the interventions. In the first study (White et al, 1999) participants had two weeks of training in computer use, well supported by a group of researchers and volunteers, and were encouraged to work together in groups. They showed a statistically significant reduction in loneliness compared to baseline, but there was no analysis against controls. In their second study (White et al, 2002), a randomised trial with approximately 50 in each of intervention and control groups, no statistically significant results were found. Yet these studies have been cited as providing evidence of the benefit of computers (Saunders, 2004) and a positive impact on the quality of life of older adults by increasing social interaction (Namazi and McClintic, 2003; Segrist, 2004; Chaffin and Harlow, 2005).

Although older adults will use computers and some will learn to use them sufficiently successfully, and will find them sufficiently useful, to continue using them after the study ends and support is withdrawn (Namazi, and McClintic, 2003), Dickinson and Gregor conclude that

"..... there is no research-based evidence to support the assertion that computer use alone has a more general (and measurable) affect on well-being among older adults. This is especially important because of the general misconception in the literature that such a connection has been found. Whether this perceived connection is used to support the introduction of potentially inappropriate interventions for older adults, or to contribute to a technocentric vision of ageing, it is important to correct it.” (page 751)

They summarise the reasons for the failure of the research to demonstrate any impact on quality of life as including: Difficulty of separating training and support effects from computer-use itself; misattribution of causality; inappropriate generalisation of results, for example, from a self-selected sample group of experienced computer users to the wider population of older people. Most results are very specific to the group study. For example, $87 \%$ of 40 'computer illiterate' frail older adults (Billipp, 2001) would not want a computer in their homes after the end of the study; whereas $82 \%$ of older people with very positive attitudes towards computer use at the beginning of the study, would miss the computer (Czaja et al, 1993).

\subsubsection{Specific uses of ICT can improve specific measures of health or wellbeing for older people}

Some simple uses of ICT have such obvious benefit that they have had widespread adoption. For example, there are currently over 300 community alarms services providing over one million people what is in effect a telecare service in response to alarms triggered by users (Curry et al, 2003). 
Magnusson and Hanson (2005) report a study that resulted in the methods being adopted as routine service in two municipalities in Sweden. The intervention consisted of a range of multimedia caring programmes that families access via their TV sets (in an EU project) and subsequently via their personal computers (PCs). The programmes were based on carers' needs identified from the empirical care-giving literature and from extensive user consultation in the project, namely, caring skills in daily life, planning ahead, respite care services, financial and economic support and coping strategies. Videophone facilities were also provided, which enabled families to have visual and oral contact with professional carers and other families involved in the project. This was achieved via a small camera on top of the PC, the installation of videoconferencing hardware on the computer and ISDN2b lines in families' homes. Finally, families also had access to Internet and e-mail facilities. The impact on quality of life was assessed by a case study and in-depth interviews with the families. Although there are limitations of small study size and in the way they calculated costs, the evidence was accepted and adopted as a mainstream service.

Various literature reviews show that ICT can have positive impact on health. But rigorous studies are expensive and it is difficult to control for confounding effects. The generalizability to other situations is often limited and even if studies are rigorous health services often fail to act on the results.

Ridley and Young (2005) in a literature review on the effectiveness of ehealth implementations in care of elderly people identified 647 primary articles of which 66 met their search criteria. Most focused on teleconference implementations, often for particular health conditions. They concluded that although there was evidence that ICT applications such as monitoring at home showed positive outcomes such as patient control, education and psychological support, greater patient functional independence, reduced emergency admissions, blood pressure control, reduced readmission rates, reduced depression, and reduced need for patient travel, many studies had limitations such as small numbers.

Jennett et al reviewed the literature on the impact of telehealth and claimed that it can improve the quality of life and health care of elderly people (Jennett et al 2003). However, a large number of such initiatives have failed, partly because they have been set up in isolation, and with little regard for their cost effectiveness (Macduff, West and Harvey, 2001).

There are rigorous studies of the impact of ICT for older patients. Jones et al (1999, 2006) studied tailored information leaflets for cancer patients. The outcome measures used were 'close' to the intervention. Tailored leaflets produced by computer are more likely to be used and are cheaper to produce than pre-printed standard booklets. They are more likely to be shared with a confidant and there is some (but inconclusive) evidence that this may improve social support or psychological state. Even with large samples, rigorous design, and specific outcome measures, positive outcomes of ICT use can be difficult to find.

\subsubsection{Could ICT lead to a reduction in quality of life for older people?}

Although many 'technophiles' seem to ignore it, the issue of the digital divide is real and significant. There is a considerable overlap in different types of ICT (ONS, 2007), with $45 \%$ of UK households in 2006 having a digital television service, as well as owning a mobile phone and having access to the Internet, while $8 \%$ did not have access to any of these ICT capabilities. While most 'divides' tend to be between rich and poor, 
north and south, the digital divide is mainly by age. In 2006, $87 \%$ of UK $16-30$ year olds had used a computer in the previous three months compared with $45 \%$ of those aged 50 and over. The figure below shows that, while the percentage of those 65 and over who have used the Internet is increasing, it is still less than a quarter of those under 25. Eventually this will reduce as cohorts age, so by 2016 we can expect at least $60 \%$ of the $65+$ age group to have used the Internet (an increase of $40 \%$ over the next ten years). However, we can also expect there to be some other new technology that will have been adopted quickly by the young and less so by the older. So unless technology development slows (unlikely) there is always likely to be technology divide between young and old. Perceptions of quality of life may be determined by comparison with others. Assuming that quality of life can be measured (see above), if more services are transferred to the Internet then those not able to access it could see a decrease in quality of life. The digital divide by age is confirmed by Selwyn et al (2003) who examined ICT access and use by older adults in their everyday lives with a sample of 352 adults aged 60+ in England and Wales. They concluded that we should refocus assumptions about older people and ICTs away from trying to 'change' older adults, and towards involving them in changing ICT.

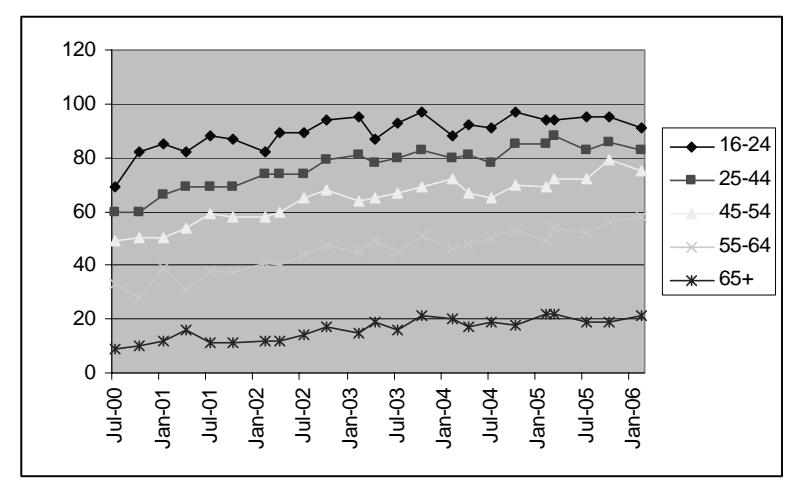

Figure 1: Percentage of different age groups in Great Britain who have ever used the Internet. (Constructed from NOS statistics http://www.statistics.gov.uk/STATBASE/ssdataset.asp?vlnk=6928

\section{Challenging Quality of Life Problems}

Nowadays it is common practice to call problems 'challenges'. Thus, in this chapter we began by noting definitional challenges, moved onto measurement challenges, and then described challenges associated with enhancing quality of life, including the potential for ICT to improve quality of life in old age. In this final section we raise a number of problems with the concept of quality of life in information and ageing societies. We have chosen to talk about problems, rather than challenges, because of the complexity of the issues and the lack of easy answers. We hope, however, that readers will keep these comments in mind whenever they encounter quality of life rhetoric. 


\subsection{Why is ICT unlikely to influence the quality of life of older people?}

ICT use by older people, or by family members and professionals on their behalf, for specific applications may have health or other specific benefits, but as we have noted in this chapter there is little research evidence demonstrating that a more general computer use has any impact on quality of life. There are three possible reasons for this.

First, it is unlikely that these specific interventions can be shown to affect, in any measurable way, quality of life because measures of quality of life are too 'remote', 'blunt', and multifactorial, to be affected.

Second, it is likely that a high quality of life brings about active ageing, healthy ageing, happiness, etc. These variables might then 'cause' people to be interested in ICT. Thus, instead of thinking of quality of life as being an outcome variable, perhaps we need to see it as either an independent/input variable, or at least as a mediating variable. It is interesting that, even though most research in the field is correlational, researchers almost always report their findings in ways which suggests that causality is obvious, with the various factors under consideration causing variation in subjective perceptions of quality of life, rather than the other way round. In other words, it is generally assumed that 'quality of life' is the 'dependent' variable in research. Thus one might take any number of variables, e.g. access to public transport, health, marriage, etc., and look to see if each is an independent predictor of 'quality of life'. It is even an underlying assumption of this book is that ICT leads to active ageing which then produces an increase in quality of life, the dependent variable.

Third, unless technological development slows the technological divide, Internet use is likely to be replaced by some other technological divide. Given that measures of quality of life are often dependent on comparisons with others, the technological divide may reduce quality of life. Moreover, if older people remain in a minority in relation to access to technology, there will always be skewing of data on the relationship between technology, ageing and quality of life. That is, there will be too few older people using the latest version of some kind of ICT to demonstrate a statistically beneficial impact on quality of life (assuming, of course, that other problems in relation to measurement are overcome).

On a more positive note, however, there are a number of studies that suggest that learning how to use computers in a supportive environment may have a positive impact on older people - maybe as much from the supportive environment as from the use of the computer. Magnusson et al (2004) reviewed ICT support for frail older people living at home and their family carers and concluded that two key themes were the importance of the user friendliness of the ICT and the transferability of findings between countries. Involving older people in the development of ICT and finding ways to bridge the generation gap so that younger people can help older people with technology are worthwhile aims. It is not clear though that the impact could be assessed using a quality of life measure.

\subsection{Is quality of life a meaningless term?}

What will, of course, be obvious to the reader is that once one begins to consider the concept in any detail it emerges as so complex and so problematic that one is left wondering, "Is 'Quality of life' a meaningless term?” If there is no agreement as to its 
definition, and many very real problems in relation to measurement, can improved quality of life be a sensible goal of policy initiatives?

We agree with Rapley (2003), that to use the quality of life construct to gauge the success of ICT, policy initiatives, services, care, education or learning, when quality of life is now viewed as an individualized aspect of the modern psyche, is paradoxical. If quality of life is individualized, is it meaningless to try and assess it in the same way for everyone? There are certainly many researchers in the field who would say that the answer to this question is 'yes, it is meaningless'. These researchers either adopt a qualitative approach or, when using a quantitative approach, argue that it is important to start by asking which factors are important for each individual and then measuring where on some scale the person's perception falls. While such an approach might be useful if one wishes to establish the perceived level of that person's quality of life (e.g. high, low or medium), such an approach makes it very difficult (though not impossible) to investigate issues such as variance in the predictors of quality of life across gender, social class, ethnicity, region, countries, etc. In other words, there are many research questions that require that the same questions be asked of all study participants and, hence, it must be assumed that most people will use most scales in roughly the same way.

The answer to the question of whether 'quality of life' is a meaningless term depends, at least partly, on whether the question is "What is quality of life?" or "What are the predictors of quality of life?” If the latter it is possible to merely define the term carefully for the study in question. Or even do as Gilhooly and her colleagues did in their studies and define quality of life as "whatever this measure of 'quality of life' measures" (Gilhooly, 2001). Because Gilhooly et al were not concerned with absolute levels of quality of life, but with variations in relationship to other measured variables, they found it unnecessary to devote time to issues of conceptualization.

The field of quality of life research shows considerable rigour of measurement, but we seem to be no closer to knowing what quality of life really 'is'. Rapley (2003) notes that instances of the use of the term show a 'family resemblance' to each other, and there is no doubt that most people have an intuitive sense of what is being talked about when the expression is used. Hence it cannot be said that it is a totally meaningless term. Our view is that the term is a short-hand, and at the same time more explicit, way of saying that 'things' are generally good or bad in life. For the social indicators movement, quality of life is a way of finding out, at a national level, if things are getting better or worse; quality of life is a way of saying that modernization is occurring. While some dispute that modernization brings about a higher quality of life, very few wish to have lived at an earlier time. In our view, the term quality of life is most meaningful in relation to social indicators and, hence, modernization. As such it is best applied at population levels, and not an individual subjective level. We do not need a concept as slippery as quality of life when what we want to measure is psychological well-being, happiness, etc. If we want to know if ICT has a positive impact on subjective well-being there are any number of good measurement tools, whose psychometric properties are well developed, from which to choose.

\subsection{Is the future bleak for old people in a modern, fast moving, information society?}

It is generally assumed that the normal declines in cognitive functioning with age put older adults at a disadvantage in a modern, post-industrial, information society. As Moody (1986) noted more than twenty years ago, an information society is inhospitable 
to old age in three ways. First, it is inhospitable because the centrality of information, especially abstract information, depreciates information derived from experience. Second, increasing speed of information transmission by electronic technology induces habits of haste and impatience with the slower learning style of later life. Third, the instantaneous propagation of information accelerates novelty and sensation of the present, with past and present absorbed by sensate immediacy. Older people feel increasingly 'left out' in such an environment. Or, as noted by two of our older Spanish friends, "We are not of this world".

Although age related declines in cognitive functioning might, by putting older people at a disadvantage in the fast and constantly changing information society, impact negatively on quality of life for older people, there are compelling arguments for why older people might have an advantage, or at least why they might not be disadvantaged. The argument for the advantage of age and experience in an information society goes as follows: Acquiring more and more information, at increasing speeds is not the same as wisdom. As noted by Naisbitt (1982) over twenty years ago, high technology not only demands 'high touch' but may stimulate greater demand for it. Thus, as high tech information becomes more common, high touch communication will become rare and precious. Moody (1986) has also pointed out that the culture of instantaneous transmission promotes an 'age irrelevant', present orientated society, where age grades are abolished or at least will be much less important.

\section{Conclusion}

The term quality of life started as a social scientific index of the relative well-being of whole populations, i.e. the state of states. Nowadays quality of life is more likely to be viewed as an individualized aspect of the modern psyche. This shift in conceptualization is problematic in that, if quality of life is individualized, it cannot be meaningful to assess it in the same way for everyone. Moreover, there are major challenges in measurement which compound the conceptual difficulties. Because wealth, health and social relations have all been found to be prime determinants of subjective quality of life, if ICTs are to enhance quality of life for older people, they need to mediate the relationships between these three important factors and quality of life. To date there is relatively little evidence that ICT has improved the quality of life of older people. One of the explanations for this lack of impact is associated with how we assess quality of life; the measures are too remote, blunt and multifactorial to be affected. The chapter is drawn to a close by asking if quality of life is a meaningless term and if the future is bleak for old people in a modern information society. The answer to both questions is no.

\section{Acknowledgments}

In this chapter we drawn on our writings from research funded by the Growing Older Programme, UK Economic and Social Research Council. In particular we have drawn on our chapter in the second GO Programme book: Gilhooly, M, Gilhooly, K and Bowling, A (2005) Quality of life: Meaning and measurement, in A Walker (ed) Understanding Quality of Life, Chapter 2, pp 14-26, Open University Press: We wish 
also to acknowledge one of our main sources, the excellent book by Mark Rapley (2003) Quality of Life Research: A Critical Introduction, Sage Publications: London.

\section{References}

Age Concern England (2007) How will the new law on age discrimination affect you? IS/17, March http://www.ageconcern.org.uk/AgeConcern/Documents/IS17AgediscriminationMar2007.pdf

Andrews, F.M. and Withey, S.B. (1976) Social indicators of well being: Americans' perceptions of life quality. New York: Plenum.

Atchley, R.C. (1980) Aging and suicide: Reflection of the quality of life. In S. Haynes and M. Feinleib (eds) Proceedings of the Second Conference on the Epidemiology of Aging. Washington, DC: US Government Printing Office

Beaumont, J.G., Kenealy, P.M. and Murrell, R.C. (2003a) Quality of life (QoL) of the healthy elder: Residential setting and social comparison processes. End of Award Report on Project L480254002 to the (UK) Economic and Social Research Council. www.regard.ac.uk

Beaumont, JG and Kenealy, PM (2003b) Quality of life of healthy older people: Residential setting and social comparison processes. Growing Older Findings 20, University of Sheffield, Sheffield, UK

Bennett, P (2003) The social context of health. In S. Llewelyn and P. Kennedy Handbook of Clinical Health Psychology. Chapter 25, John Wiley \& Sons, 502-518.

Billipp, S.H. (2001). The psychosocial impact of interactive computer use within a vulnerable elderly population: a report on a randomized prospective trial in a home health care setting. Public Health Nursing 18, 138-145.

Blane, D, Davey Smith, G and Bartley, M (1993) Social selection: what does it contribute to social class differences in health? Sociology of Health and Illness, 15, 1-15

Blane, D., Wiggins, R., Higgs, P. and Hyde, M. (2002) Inequalities in quality of life in early old age. Research Findings from the Growing Older Programme. 9

Blazer, D.C. and Williams, C.D. (1980) Epidemiology of dysphoria and depression in the elderly populations. American Journal of Psychiatry. 137, 439-444.

Bowling, A and Gabriel, Z (2004). An integrational model of quality of life in older age: A comparison of analytic and lay models of quality of life. Social Indicators Research, 69: 1-36.

Bowling, A., Farguhar, M. and Browne, P. (1991) Life satisfaction and associations with social network and support variables in three samples of elderly people. International Journal of Geriatric Psychiatry. Vol 6, 549-566.

Bowling, A. and Browne, P. (1991) Social support and emotional well-being among the oldest old living in London. Journal of Gerontology, 46-20-32

Brandstädter, J. and Baltes-Gotz, B. (1990) Personal control over development and quality of life perspectives in adulthood. In P.B. Baltes and M.M. Baltes (eds) Successful Aging: Perspectives from the Behavioral Sciences. Cambridge: Cambridge University Press.

Brody, J.A. (1990) Chronic diseases and disorders. In A.L. Goldstein (ed) Biomedical Advances in Ageing. New York: Plenum Press, 137-142.

Campbell, A. (1981) The Sense of Well-being in America. New York: McGraw-Hill.

Chaffin, A.J. and Harlow, S.D., (2005). Cognitive learning applied to older adult learners and technology. Educational Gerontology, 31 (4), 301-329.

Chambers Twentieth Century Dictionary, Revised Edition. (1961) Edinburgh, UK: W \& R Chambers.

Chung, M.C., Killingworth, A. and Nolan, P. (1997) A critique of the concept of quality of life, International Journal of Health Care Quality Assurance, 10(2): 80-84.

Cobb, S. (1976) Social support as a moderator of life stress. Psychosomatic Medicine. 38, 300-314.

Cohen, S. (2004) Social relationship and health. American Psychologist, 59, 676-684.

Commission of the European Communities (2007a) Ageing well in the Information Society. An i2010 Initiative. Action Plan on Information and Communication Technologies and Ageing, SEC (2007) 811 Communication from the Commission to the European Parliament, the Council, the European Economic and Social Committee and the Committee of the Regions,

Commission of the European Communities (2007b) Ageing well in the Information Society. An i2010 Initiative. Action Plan on Information and Communication Technologies and Ageing, SEC (2007) 811 Communication from the Commission to the European Parliament, the Council, the European Economic and Social Committee and the Committee of the Regions, (Brussels, 14 June 2007, IP/07/831) Press release 
Costa, P.T. and McCrae, R.R. (1980) Influence of extraversion and introversion on subjective well-being: Happy and unhappy people. Journal of Personality and Social Psychology, 38, 668-678.

Costa P.T., McCrae, R.R. and Zonderman, A.B. (1987) Environmental and dispositional influences on wellbeing: Longitudinal follow-up of an American national sample. British Journal of Psychology, 78,299306.

Cristofalo, V.J., Tresini, M., Francis, M.K. and Volker, C. (1999) Biological theories of senescence. In V L Bengtson and K W Schaie (eds) Handbook of Theories of Aging. New York: Springer Publishing. Chapter 6, pp 98-112.

Curry, R.G., Trejo Tinoco M., and Wardle D., (2003). Telecare: Using information and communication technology to support independent living by older, disabled and vulnerable people. Department of Health Report July 2003. www.icesdoh.org.uk/downloads/ICT-Older-People-July-2003.pdf

Czaja, S.J., Guerrier, J.H., Nair, S.N., and Landauer, T.K., (1993) Computer communication as an aid to independence for older adults. Behaviour and Information Technology 12, 194-207.

Danowski, J.A. and Sacks, W., (1980) Computer communication and the elderly. Experimental Aging Research 6 (2), 125-135.

DeMaio, T.J. (1984) Social desirability and survey measurement: a review. In C.F. Turner and E. Martin (eds) Surveying subjective phenomena, Vol. 2. New York: Russell Sage Foundation.

Dickinson A, Gregor P. (2006) Computer use has no demonstrated impact on the well-being of older adults Int. J. Human-Computer Studies, 64, 744-753.

Diener, E. (1984) Subjective well-being, Psychological Bulletin, 235: 542-75.

Diener, E. (2000) Subjective well-being: The science of happiness and a proposal for a national index in M.E.P. Seligman and M. Csikszentmihalyi (eds) Special Issue on Happiness, Excellence, and Optimal Human Functioning. American Psychologist, 55, January: 34-43.

Diener, E. and Lucas, R.E. (1999) Personality and subjective well-being in D. Kahneman, D.E. Diener and. N. Schwarz (eds) Well-Being: The Foundations of Hedonic Psychology. New York: Russell Sage Foundation: 13-229.

Elder, G.H. (1974) Children of the Great Depression. Chicago: University of Chicago Press.

Evans, D.R. (1994) Enhancing quality of life in the population at large. Social Indicators Research, 33, 4788.

Evans, D.R., Pellizzari, J.R., Culbert, B.J. and Meten, M.E. (1993) Personality, marital and occupational factors associated with quality of life. Journal of Clinical Psychology, 49, 153-485.

Gabriel, Z. and Bowling, A. (2004) Quality of Life in Old Age from the Perspectives of Older People. In A Walker and CH Hennessy, C H (eds) Growing Older: Quality of Life in Old age. Open University Press, Chapter 2.

Gee, E. (2000) Living arrangements and quality of life among Chinese Canadian elders. Social Indicators Research, 51, 309-329

George, L.K. (1980) Role transitions in later life. Belmont, CA; Wadsworth.

Gilhooly, M. (2001) Quality of life and real life cognitive functioning. Growing Older Programme Newsletter, 2: 6

Gilhooly, M.L., Gilhooly, K.J., Phillips, L.H., Harvey, D., Brady, A. and Hanlon, P. (2007) Real-world problem solving and quality of life in older people. British Journal of Health Psychology. 12, 587-600.

Gilhooly, M. and Lightbody, P. (1999) Intelligence. In M Porter, B Alder, and C Abraham (1999) Psychology and Sociology Applied to Medicine. Churchill Livingston: London, pp 30-31.

Gilhooly, M. and McDonach, E. (2006) An average old age: Associations between ageing, health and behaviour. In S.P. Llewelyn, and P. Kennedy (eds) Essential Handbook of Clinical Health Psychology. John Wiley and Sons, Ltd: Chichester.

Gilhooly, M., Gilhooly, K. and Bowling, A. (2005) Quality of life: Meaning and measurement. In A Walker (ed) Understanding Quality of Life, Chapter 2, pp14-26m Open University Press:

Gilhooly, M., Hamilton, K., O’Neill, M., Gow, J., Webster, N. and Pike, F. (2002a). Transport and ageing: Extending quality of life via public and private transport. Research Findings from the Growing Older Programme: 16 ,

Gilhooly, M., Phillips, L., Gilhooly, K., and Hanlon, P. (2002b). Quality of life and real life cognitive functioning. Research Findings from the Growing Older Programme: 15.

Gilhooly, K., Gilhooly, M., Phillips, L., and Hanlon, P (2003). Use it or lose it? Cognitive functioning in older adults. Nursing and Residential Care, 5: 392-395.

Gompertz, S. (1825) On the expressive law of human mortality and a new mode of determining the value of life contingency. Philosophical Transactions of the Royal Society of London, 115, 513-585.

Gow, A.J., Whiteman, M.C., Pattie, A. Whalley, L., Starr, J., and Deary, I.J. (2005) Life time intellectual function and satisfaction with life in old age: longitudinal cohort study. BMJ, 2005; 331;141-142

Gow, J. and Gilhooly, M. (2003) Risk Factors for Dementia and Cognitive Failure in Old Age. NHS Health Scotland: Clifton House, Glasgow 
The Health and Retirement Study (2007) National Institute on Aging, National Institutes of Health, US Department of Health and Human Services. NIH Publication NO 07-57-57, Mary

Horn, J.L. (1982) The theory of fluid and crystallized intelligence in relation to concepts of cognitive psychology and aging. In F. Craik and S. Trehub (eds) Aging and Cognitive Processes. New York: Plenum Press.

Hyde, M., Wiggins, R.D., Higgs, P. and Blane, D.B. (2003). A measure of quality of life in early old age: the theory, development and properties of a needs satisfaction model (CASP-19). Ageing and Mental Health, 7 (3) 186-194.

Hyde, M., Blane, D., Higgs, P. and Wiggins, R. (2001). The theory and properties of a needs satisfaction model of quality of life. Growing Older Programme Newsletter, 3: 4.

Jarvik, L.F. and Perl, M. (1981) Overview of physiological dysfunctions related to psychiatric problems in the elderly. In A. Levenson and R.C.W. Hall (eds) Psychiatric management of physical disease in the elderly, New York: Raven Press.

Jennett, P.A., Affleck Hall, L., Hailey, D., Ohinmaa, A., Anderson, C., Thomas, R., Young, B., Lorenzetti, D. and Scott, R.E. (2003) 'The socio-economic impact of telehealth: a systematic review'. Journal of Telemedicine and Telecare. 9(6), 311-320.

Jones, B., and Bayen, U., (1998) Teaching older adults to use computers. Educational Gerontology 24, 675689.

Jones, R., Pearson, J., McGregor, S., Cawsey, A., Barrett, A., Atkinson, J.M., et al. (1999). Randomised trial of personalised computer-based information for cancer patients. British Medical Journal 319:12411247.

Jones, R.B., Pearson, J., Cawsey, A.J., Bental, D., Barrett, A., White, J., White C.A., Gilmour, W.H. (2006) Effect of different forms of information produced for cancer patients on their use of the information, social support, and anxiety: randomised trial. BMJ, 332: 942 - 948.

JRF (Joseph Rowntree Foundation) (2001) Age discrimination legislation: choices for the UK. Findings, July www.jrf.org.uk

Kafetsios, K. (2006) Social support and well-being in contemporary Greek society: Examination of multiple indicators at different levels of analysis. Social Indicator Research, 76, 127-145.

Kahneman, D., Frederickson, B.L., Schreiber, C.A. and Redelmeier, D.A. (1993) When more pain is preferred to less: adding a better end, Psychological Science, 4: 401-5.

Kasl, S.V. and Rosenfield, S. (1980) The residential environment and its impact on the mental health of the aged. In J.E. Birren and R.B. Sloan (eds) Handbook of mental health and aging. Englewood Cliffs, N.J.: Prentice-Hall.

Kubovy, M. (1999) On the pleasures of the mind in D. Kahneman, D.E. Diener, and N. Schwarz (eds) WellBeing: The Foundations of Hedonic Psychology. New York: Russell Sage Foundation: 134-154.

Land, K. (2000) Social indicators. www.cob.vt.edu/market/isqols/kenlandessay.htm

Lazarus, R.S. (1991a) Cognition and motivation in emotion. American Psychologist, 46, 352-367

Lazarus, R.S. (1991b) Emotion and adaptation. Oxford University Press: Oxford

Leveton, L.B., Griffin, R.M. and Douglas, T.J. (1979) Social supports and well-being in urban elderly. Unpublished manuscript cited by Fiore, J., Coppel, D.B. Becker J. et al (1986) Social support as a multifaceted concept. Examination of important dimensions for adjustment. American Journal of Community Psychology 143, 93-111

Manton, K. (1989) Epidemiological, demographic and social correlates of disability among the elderly, The Millbank Quarterly, 67, (Siupp.2 PI), 13-58

Macduff, C., West, B., and Harvey, S. (2001) 'Telemedicine in rural care. Part 2: Assessing the wider issues. 15(33), 33-38.

Magnusson, L., Hanson, E., and Borg, M. (2004). A literature review study of Information and Communication Technology as a support for frail older people living at home and their family carers. Technology and Disability Volume 16, Number 4 / 2004, 223 - 235.

Magnusson L., and Hanson E. (2005) Supporting frail older people and their family carers at home using information and communication technology: cost analysis. Journal of Advanced Nursing, 51 (6), 645657.

McCarron, P., Davey Smith, G. and Wormsley, J. (1994) Deprivation and mortality in Glasgow: Changes from 1980 to 1992. British Medical Journal, 309, 1481-1482.

Miller, R.A. (1994) The biology of ageing and longevity. In W.R. Hazzard, E.L. Bierman, et al (eds) Principle of geriatric medicine and gerontology. (3rd edition), New York: McGraw Hill, pp 3-18.

Mitchell, J.C. (1969) The concept and use of social networks. In J.C. Mitchell, (Ed) Social networks in urban situations; analysis of personal relationships in Central African Towns, Manchester University Press, Manchester.

Moody, H.R. (1986) Late life learning in the information society. In D.A. Peterson, J.E. Thornton and JE Birren (eds) Education and Ageing Englewood Cliffs: Prentice-Hall Inc. Chapter 5, pp122-148. 
Myers, D.G. (2000) The funds, friends, and faith of happy people in M.E.P. Seligman and M. Csikszentmihalyi (eds) Special Issue on Happiness, Excellence, and Optimal Human Functioning. American Psychologist, 55, January: 56-67.

Myers, D.G. and Diener, E. (1996) The pursuit of happiness, Scientific American, 274: 54-6.

Naisbitt, J. (1982) Megatrends: Ten New Directions Transforming our Lives. New York: Warner Books.

Namazi, K.H., McClintic, M., (2003) Computer use among elderly persons in long-term care facilities. Educational Gerontology 29, 535-550

National Institute on Aging (2007) Growing Older in America: The Health and Retirement Study. National Institute on Ageing, US Department of Health and Human Services. NIH Publication No 07-5757. http://www.nia.nih.gov/ResearchInformation/ExtramuralPrograms/BehavioralAndSocialResearch/HRS. htm

Nazroo, J., Bajekal, M., Blane, Grewal, I. and Lewis, J. (2003) Ethnic inequalities in quality of life at older ages: subjective and objective components. Research Findings: 11 From the Growing Older Programme, January. www.shef.ac.uk/uni/projects/gop/index/htm

Netuveli, G. (2007) Welfare regimes hold the key to a better old age. Report in The Edge. Newsletter of the UK Economic and Social Research Council, Issue 25, page 22.

Office for National Statistics (2007) Use of ICT at home. Focus on the Digital Age. National Statistics Online. http://www.statistics.gov.uk/cci/nugget.asp?id=1710

Pensions Commission - Chair, Adair Turner (2004) Pension: Challenges and Choices: The First Report of the Pensions Commission, London: HMSO.

Pensions Commission - Chair, Adair Turner (2005) A New Pension Settlement for the Twenty-First Century: The Second Report of the Pensions Commission.. London: HMSO

Pensions Commission - Chair, Adair Turner (2006) Implementing and Integrated Package of Pension Reforms: The Final Report of the Pensions Commission, London: HMSO.

Prince, M.J., Harwood, R.H., Blizard, R.A., Thomas, A. and Mann, A.H. (1997) Social support deficits, loneliness and life events as risk factors for depression in old age. The Gospel Oak Project VI. Psychological Medicine, 27, 323-332.

Quick, H.E. and Moen, P. (1998) Gender, employment, and retirement quality: a life course approach to the differential experiences of men and women. Journal of Occupational Health Psychology, Jan; 3(1) 4464.

Rapley, M. (2003) Quality of Life Research: A Critical Introduction, Sage Publications: London.

Ridley, G. and Young, J. (2005) Outcomes of International Ehealth Implementations in Aged Care. School of Information Systems University of Tasmania eprints. http://eprints.utas.edu.au/

Ross, M., Eyman, A., and Kishchuck, N. (1986) Determinants of subjective well-being in J.M. Olson, C.P. Herman and M. Zanna (eds) Relative deprivation and social comparison. Hillsdale, N.J.: Erlbaum.

Runyan, W.M. (1980) The life satisfaction chart: perceptions of the course of subjective experience, International Journal of Aging and Human Development, 11: 45-64.

Ryan, R.M. and Deci, E.L. (2000) Self-determination theory and the facilitation of intrinsic motivation, social development, and well-being in M.E.P. Seligman and M. Csikszentmihalyi (eds) Special Issue on Happiness, Excellence, and Optimal Human Functioning. American Psychologist, 55: 68-78.

Ryan, R.M. and Deci, E.L. (2001) On happiness and human potential: A review of research on hedonic and eudaimonic well-being, Annual Review of Psychology, 52: 141-166.

Ryff, C.D. and Singer, B. (1998) The contours of positive human health, Psychological Inquiry, 9: 1-28.

Ryff, C.D. and Singer, B. (2000) Interpersonal flourishing: a positive health agenda for the new millennium, Personality and Social Psychology Review, 4: 30-44

Saunders, E.J., 2004. Maximizing computer use among the elderly in rural senior centers. Educational Gerontology 30, 573-585.

Scheier, M.F. and Carver, C.S. (1985). Optimism, coping and health: assessment and implications of generalised outcome expectancies. Health Psychology 4: 219-47.

Scheier, M.F.K., Matthews, K.A., Owens, J.F., Magovern, G.J., et al (1989) Dispositional optimism and recovery from coronary artery bypass surgery: The beneficial effects on psychical and psychological well-being. Journal of Personality and Social Psychology, 57, 1024-1040.

Schwartz, N. (1987) Mood as Information. Heidelberg: Springer-Verlag

Schwartz, N. and Clore, G.L. (1983) Mood, misattribution and judgments of well-being: informative and directive functions of affective states, Journal of Personality and Social Psychology, 45: 513-23.

Schwartz, N. and Strack, F. (1991) Context effects in attitude surveys: applying cognitive theory to social research in W. Stroebe and M. Hewstone (eds) European Review of Social Psychology, Vol. 2. Chichester: J Wiley.

Schwartz, N., Strack, F. and Mai, H.P. (1991) Assimilation and contrast effects in part-whole question sequences: a conversational logic hypothesis, Public Opinion Quarterly, 55: 2-23. 
Segrist, K.A., (2004) Attitudes of older adults toward a computer training program. Educational Gerontology 30, 563-571.

Selwyn, N., Gorard, S., Furlong, J., and Madden, L. (2003). Older adults' use of information and communications technology in everyday life. Ageing \& Society 23, 2003, 561-582.

Smith, T.W. (1979) Happiness, Social Psychology Quarterly, 42: 18-30.

Soloman, D.H. (1999) The role of aging processes in aging-dependent diseases. In V.L. Bengtson and K.W. Schaie (eds) Handbook of Theories of Aging. New York: Springer Publishing. Chapter 8, pp 133-150.

Strack, F., Martin, L.L. and Schwartz, N. (1988) Priming and communication: Social determinants of information use in judgments of life satisfaction. European Journal of Social Psychology, 18, 429-42.

Strack, Schwartz, N., Chassein, B., Kern, D. and Wagner, D. (1990) The salience of comparison standards and the activation of social norms: consequences for judgments of happiness and their communication, British Journal of Social Psychology, 29: 303-14.

Suthers, K., Jung, K.K., Crimmins, E. (2003) Life expectancy with cognitive impairment in the older population of the United States. The Journals of Gerontology: Social Sciences, 58B/3, S179-186. Reported in National Institute on Aging (2007) Growing Older in America: The Health and Retirement Study. National Institute on Aging, US Department of Health and Human Services. NIH Publication No $07-5757$ www.nia.nih.gov/ResearchInformation/ExtramuralPrograms/BehavioralAndSocialResearch/HRS.htm

Teri, L. (1991) Behavioral assessment and treatment of depression in older adults. In P.A. Wisocki (ed) Handbook of Clinical Behavior Therapy with the Elderly Client, pp 225-244.

Walker, A. (1993) Poverty and inequality in old age. In J. Bond, P. Coleman and S. Peace (eds). (1993) Ageing in Society: And Introduction to Social Gerontology. London: Sage Publications.

Walker, A. (2001). Introduction to the Second Newsletter of the Growing Older Programme: Defining Quality of Life. Growing Older Programme Newsletter, 2: 1.

Walker, A. and Hennessy, C.H. (eds). (2004) Growing Older: Quality of Life in Old age. Open University Press.

Wallston, B.S., Alagna, S.W., Devellis, B.M., and Devellis, R.F. (1983) Social support and physical illness. Health Psychology, 2, 367-391.

Wan, T.T.H. (1987) Functionally disabled elderly: Health status, social support and use of health services. Research on Ageing. 9, 61-78

Waterman, A.S. (1993) Two conceptions of happiness: Contrasts of personal expressiveness and hedonic enjoyment, Journal of Personality and Social Psychology, 64: 678-691.

Wenger, C.C. (1984) The Supportive Network, Coping with Old Age National Institute of Social Services Library, No 46, Allen and Unwin: London.

White, H., McConnell, E., Clipp, E., Bynum, L., Teague, C., Navas, L., Craven, S., Halbrecht, H., (1999). Surfing the net in later life: a review of the literature and pilot study of computer use and quality of life. The Journal of Applied Gerontology 18, 358-378.

White, H., McConnell, E., Clipp, E., Branch, L.G., Sloane, R., Pieper, C., Box, T.L., (2002). A randomized controlled study of the psychosocial impact of providing internet training and access to older adults. Aging and Mental Health 6, 213-221.

Wilkinson, R.G. (1996) Unhealthy Societies: The Afflictions of Inequality. London: Routledge.

Willis, S.L. (1985) Towards and educational psychology of the older adult learner: Intellectual and cognitive bases. In J.E. Birren and K.W. Schaie (eds). Handbook of the Psychology of Ageing. New York: Van Nostrand Reinhold.

Wood, R. and Bain, M. (2001) The Health and Well-Being of Older People in Scotland: Insights from National Data. Information and Statistics Division, Common Services Agency for NHS Scotland: Edinburgh.

World Health Organization Quality of Life Group (1993) Measuring Quality of Life: The Development of the World Health Organization Quality of Life Instrument (WHOQOL). Geneva: World Health Organization.

World Health Organization (2007) Basic Documents. 46the Edition, Constitution of the World Health Organization. Page 1. http://www.who.int/gb/bd/E/index.html

Young, M.Y. (1991) The adjustment of Salvadorian refugees: Stressors, resources and well-being. Unpublished doctoral dissertation. The University of Western Ontario, London, Ontario, Canada. 